\title{
温排水の水中放流による局所洗掘現象の数値解析 \\ Prediction of Local Scour Caused by Warmed Cooling-Water Jets
}

\author{
牛島 省* 清水 隆夫**、佐々木 明***、䇥澤 靖彦****
}

By Satoru USHIJIMA, Takao SHIMIZU,Akira SASAKI and Yasuhiko TAKIZAWA

\begin{abstract}
This paper describes an investigation on a numerical prediction method to estimate local scour due to the cooling-water jets discharged from power stations. The method presented simulates the unsteady convection and diffusion processes of the warmed jets with a two-equation turbulence model within the calculation area being deformed by the local scour. The profile of the scoured sand bed is predicted by computing the amount of both the bed load and the suspended load in parallel with the simulation of the flow itself. The prediction method was applied to the experiments and its validity was reasonably confirmed.
\end{abstract}

Keywords : numerical prediction, local scour, warmed cooling water, turbulence model

\section{1.はじめに}

発電施設から温排水が高流速で水中放流される際に、その前面の海底が微細な砂から構成されている場合 には、海底面が局所的に洗掘されて柾造物等に影警が及ぼされる可能性がある。このため、放流施設等の構 造物の安定性を評価したり、洗掘に対する防讙対策を考えたりする上で、局所洗掘現象による海底面の洗掘 深さや洗掘される䡉囲などをあらかじめ予测しておくことが重要である。

噴流によって生ずる局所洗掘現象に関しては、これまでに実験的・理論的な研究が数多く行なわれてきて

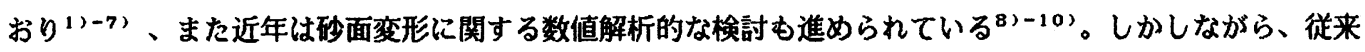
の研究結果のみから発電施設現場の局所洗掘現象を予测することは容易でないと思われたため、電中研では 温排水の移流拡散と砂面の変形を同時に数值解析する手法の検討を行なった。

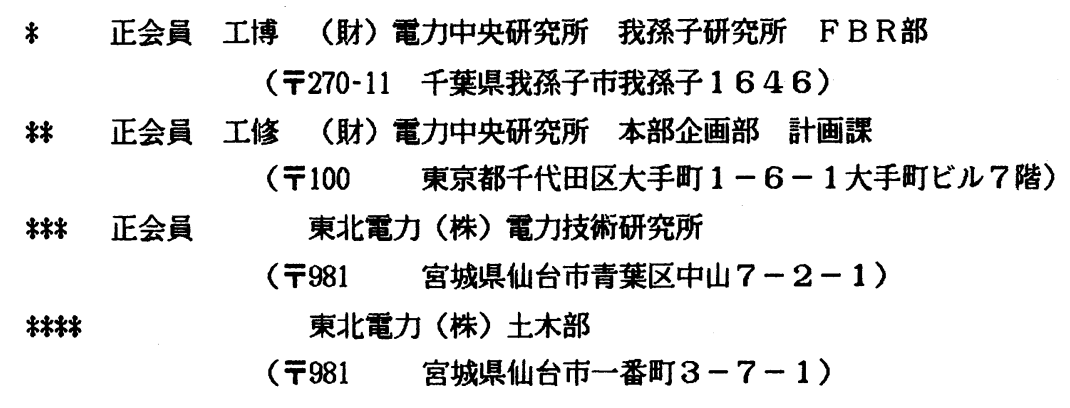




\section{2. 局所洗掘現象の解析手法}

\section{1 渴排水の移流拡散の解析方法}

発電施設から海へ放出される温排水の移流拡散を計算するための解析モデルに関しては、これまで多くの 研究が行われている11-15)。本研究で用いるのは、乱流拡散係数等に対する浮力の効果を考磨した 2 方程式

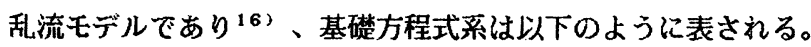

$$
\begin{aligned}
& \frac{\partial U_{1}}{\partial x_{1}}=0 \quad \cdots(1), \quad \frac{\partial \Theta}{\partial t}+U_{1} \frac{\partial \Theta}{\partial x_{j}}=\frac{\partial}{\partial x_{j}}\left(\alpha \frac{\partial \Theta}{\partial x_{j}}-\overline{u_{j} \theta}\right) \\
& \frac{\partial U_{1}}{\partial t}+U_{1} \frac{\partial U_{1}}{\partial x_{1}}=-\left[1-\beta\left(\Theta-\Theta_{s}\right)\right] \delta_{13} g-\frac{1}{\rho} \frac{\partial P}{\partial x_{1}}+\frac{\partial}{\partial x_{1}}\left(\nu \frac{\partial U_{1}}{\partial x_{j}}-\overline{u_{1} u_{3}}\right) \\
& \frac{\partial \mathrm{k}}{\partial \mathrm{t}}+\mathrm{U}_{\mathrm{i}} \frac{\partial \mathrm{k}}{\partial \mathrm{x}_{1}}=-\overline{\mathrm{u}_{1} \mathrm{u}_{\mathrm{j}}} \frac{\partial \mathrm{U}_{1}}{\partial \mathrm{x}_{\mathrm{j}}}+\beta \mathrm{g} \overline{\mathrm{u}_{3} \theta}+\frac{\partial}{\partial \mathrm{x}_{3}}\left[\left(\nu+\mathrm{C}_{\mathrm{k}} \frac{\mathrm{k}^{2}}{\varepsilon}\right) \frac{\partial \mathrm{k}}{\partial \mathrm{x}_{\mathrm{j}}}\right]-\varepsilon \\
& \frac{\partial \varepsilon}{\partial \mathrm{t}}+\mathrm{U}_{1} \frac{\partial \varepsilon}{\partial \mathrm{x}_{j}}=\mathrm{C}_{\varepsilon_{1}} \frac{\varepsilon}{\mathrm{k}}\left(-\overline{\mathrm{u}_{1} \mathrm{u}_{3}} \frac{\partial U_{1}}{\partial \mathrm{x}_{j}}\right)+\mathrm{C}_{\varepsilon_{2}} \frac{\varepsilon^{2}}{\mathrm{k}}+\frac{\partial}{\partial \mathrm{x}_{j}}\left[\left(\nu+\mathrm{C}_{\varepsilon} \frac{\mathrm{k}^{2}}{\varepsilon}\right) \frac{\partial \varepsilon}{\partial \mathrm{x}_{j}}\right]
\end{aligned}
$$

これらの方程式中で、 $t:$ 時間、 $x_{1}: i$ 座標であり、 $x_{1}$ :水平・流下方向、 $x_{2}$ :水平・横断方向、 $x_{3}$ : 鉛直 上方向に向かう座標成分である。また、本報中では、 $x_{1} 、 x_{2} 、 x_{3}$ は，それぞれ $x_{1} 、 y 、 z$ と表示され る。さらに、 $\mathrm{U}_{1}$ : 平均流速の $\mathrm{i}$ 成分、 $u_{1}$ : 変動流速の $\mathrm{i}$ 成分、 $\Theta:$ : 温度の平均成分、 $\theta:$ : 温度の変動成 分、 $\Theta_{\mathrm{s}}$ : 基準温度、 $\mathrm{P}:$ 圧力の平均成分、 $\mathrm{k}$ : 乱れの運動エネルギー、 $\varepsilon$ : 乱れエネルギーの散逸率、 $\alpha$ : 熱搪散係数、 $\beta$ : 熱膨張係数、 $\nu$ : 動粘性係数、 $\rho$ : 流体の密度、 $g$ : 重力加速度、 $\delta_{1 \jmath}:$ クロネッカー のデルタである。式中で上付きバーは平均成分をとることを意味する。また、これらの方程式中では、同一 項内に現われるサフィックスに対して、3次元成分の和をとるという規約が用いられている。上式中のレイ ノルズ応力、乱流熱フラックスは、ブシネスクの仮説により与えられる。また、(4)、(5)式中で、 $C_{k} 、 C \varepsilon 、$ $C \varepsilon_{1}$ およびC $\varepsilon_{2}$ は、モデル係数である（ $\left.C_{k}=0.09, C \varepsilon=0.075, C \varepsilon_{1}=1.44, C \varepsilon_{2}=1.90\right)$ 。佩動粘性係数 $\left(\varepsilon_{M}\right)$ と渦動熱拡散係数 $\left(\varepsilon_{\mathrm{H}}\right)$ は、成層流実験の結果 ${ }^{16)}$ に基づき、それぞれ以下のように表されるものとした。

$$
\varepsilon_{M}=C v \frac{1}{1+0.2 B_{L}} \frac{k^{2}}{\varepsilon} \cdots(6), \varepsilon_{H}=\frac{1.6}{1+0.24 B_{1}} \varepsilon_{M} \cdots(7), B_{L}=\beta g\left(\frac{k}{\varepsilon}\right)^{2} \frac{\partial \Theta}{\partial z} \cdots(8)
$$

ここでCעは係数(0.09)であり、Bし はLaunder 17)により提案された成層度の強弱を表すパラメータであ る。 $\mathrm{B}_{\mathrm{I}}$ ＜0となる場合では、(6)、(7) 式で $\mathrm{B}_{\mathrm{L}}=0$ とした形の関係式を用いる。なお、後述するように流 れの中には浮遊砂が含まれる場合があるが、流れに対する浮遊砂の影㿞はここでは考慮していない。

数值解析は有限差分法(FDM) に基づく。運動方程式は、時間的にはセミ・インプリシット法により差分化 されており、運動方程式と連続式から導かれる圧力のポアソン方程式の解法には、収束性の良い前処理付き の双対共役勾配法(MILUBCG法)を用いた。

\section{2 洗掘される砂面形状の解析方法}

砂の移動形熊としては、掃流移動と浮遊移動を考える。

(a) 掃流砂量の算出式

掃流砂量式に関しては、多くのものが提案されている。局所洗掘が生ずる際には複雑な砂面形状が現れる が、ここでは芦田ら ${ }^{18)}$ が平坦な河床を対象として提案した次式を用いることとした。

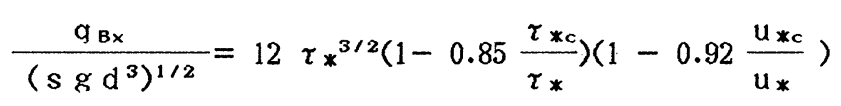

ここに $\sigma$ は砂の密度、 $d$ は砂の平均粒径である $\left(\sigma=2.65 \mathrm{~g} / \mathrm{cm}^{3}, \mathrm{~d}=0.2 \mathrm{~mm}\right) 。 \mathrm{q}_{\mathrm{B} \times}$ は単位時間・単位幅

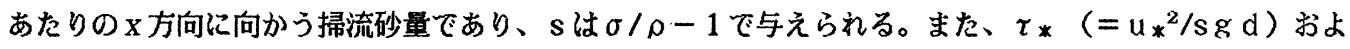
び $\tau_{*_{c}}\left(=u_{*_{c}}{ }^{2} / s \mathrm{~g} d\right)$ は、それぞれ無次元の掃流力と砂に対する限界掃流力である。限界掃流力は、岩 
垣公式による限界まさつ速度 $u_{* c}$ を用いて求められた。まさつ速度 $u_{*}$ に関しては、これまでに多くの詳細 な検討がなされているが、ここでは簡単に1/7 乗則を参考とした次式により与えられるものとした。

$$
\frac{\mathrm{U}_{\mathrm{s}}}{\mathrm{U}_{*}}=\mathrm{A}_{1}\left(\frac{Z_{\mathrm{B}}}{\mathrm{k}_{\mathrm{s}}}\right)^{1 / 7}
$$

ここでし の距離である。 $\mathrm{k}_{\mathrm{s}}$ は底面粗度で、ここでは砂の粒径と同じ值とした。上式中の係数 $\mathrm{A}_{1}$ の值(0.2) はパラメ 一タサーベイにより決定された。以上の諸関係式より掃流砂量 $\mathrm{q}_{\mathrm{B} \times}$ 氒求められる。これらと同様にして、y 方向のまさつ速度 $\mathrm{v}$ *から $\mathrm{y}$ 方向の掃流砂量 $\mathrm{q}_{\mathrm{B}}$ 女計算される。

(b) 浮遊砂量の算出式

浮遊砂謴度の輪送過程は、次式で表わされる19?。

$$
\frac{\partial \mathrm{C}}{\partial \mathrm{t}}+\left(\mathrm{U}_{\jmath}-\mathrm{W}_{0} \delta_{3 \jmath}\right) \frac{\partial \mathrm{C}}{\partial \mathrm{x}_{\jmath}}=\frac{\partial}{\partial \mathrm{x}_{\jmath}}\left[\left(\lambda+\varepsilon_{s}\right) \frac{\partial \mathrm{C}}{\partial \mathrm{x}_{\jmath}}\right]
$$

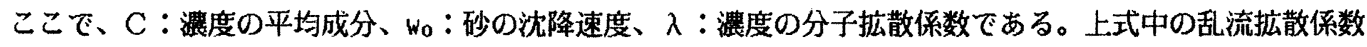
$\varepsilon_{\mathrm{s}}$ は乱流シュミット数 $\mathrm{s}_{\mathrm{t}}$ を用いて、 $\varepsilon_{\mathrm{s}}=\varepsilon_{\mathrm{M}} / \mathrm{s}_{\mathrm{t}}$ で与えられる。乱流シュミット数は、乱流プラントル数 と同様に浮力の影響を受けると考えられるが、ここでは定数(1.0)とした。浮遊砂の平均濃度の輸送方程式 は、流体の基礎方程式と同様に差分化して、それらと同時に解かれる。得られた浿度分布を用いて、たとえ ば単位時間あたりに奥行単位長さの鉛直断面内（水深h)を通過する $\mathrm{x}$ 方向の浮遊砂量 $\mathrm{qs}_{\mathbf{x}}$ は、次式から計算 される。

$$
\mathrm{q}_{\mathrm{s} \times}=\int_{0}^{\mathrm{h}} \frac{\mathrm{UC}}{\sigma} \mathrm{dz}
$$

これと同様にして、y方向の浮遊砂量のフラックス $\mathrm{q}_{\mathrm{s} y}$ も計算される。（12）式を解く際に、境界条件とし て砂面のごく近傍の浮遊砂の䀧度C 0 を与えるが、このために本研究では、Lane\& Kal inske ${ }^{20}$ モデルを用い た。このモデルでは、Co（単位:ppm）は次式で与えられる。

$$
\mathrm{C}_{0}=5.55 \Delta \mathrm{F}\left(\mathrm{w}_{0}\right)\left[\frac{1}{2} \frac{\mathrm{u}_{*}}{\mathrm{w}_{0}} \exp \left(-\mathrm{w}_{0}^{2} / \mathrm{u}_{*}^{2}\right)\right]^{1.61}
$$

ここで $\Delta F\left(W_{0}\right)$ は、沈降速度がW。なる砂が全砂㹸中に占める割合（\%值：ここでは100)である。

(c) 砂面近傍の境界条件

流体の計算に用いる諸变数のうち, 各流速成分は計算セルの各面上で定義され、圧力 $\mathrm{P}_{1}$ 小k はセルの中心 で定義される。圧力以外のスカラー量む圧力と同じ位置に定義 される。図 1 は、 $x y$ 平面上における砂面の高さBと、 $\mathrm{x}$ およ び y方向の総移動砂量 $q_{x} q_{y}$ の定義位置を示すものである。 $q_{x}$ と $q_{y}$ は、それぞれ同方向の掃流砂量 $q_{B \times}, q_{B y}$ と浮遊砂 量 $q_{s_{x}} 、 q_{s_{y}}$ の和として表される $\left(q_{i}=q_{B_{i}}+q_{s_{i}}\right)$ 。四中 で、実線で描かれた部分が、流体の計算スキームであり、また 破線で囲んだ領域が移動砂荲の連続性を考える $\mathrm{x} \mathrm{y}$ 平面内のコ ントロールボリュームに相当する。砂のポロシティーケが、砂 の移動前後で変化ないと仮定すると、Bと $\mathrm{q}_{x}$ および $\mathrm{q}_{\mathrm{y}}$ の関 係は次のように表される19>。

$$
(1-r) \frac{\partial \mathrm{B}}{\partial \mathrm{t}}=\frac{\partial \mathrm{q}_{\mathrm{x}}}{\partial \mathrm{x}}+\frac{\partial \mathrm{q}_{\mathrm{y}}}{\partial \mathrm{y}}
$$

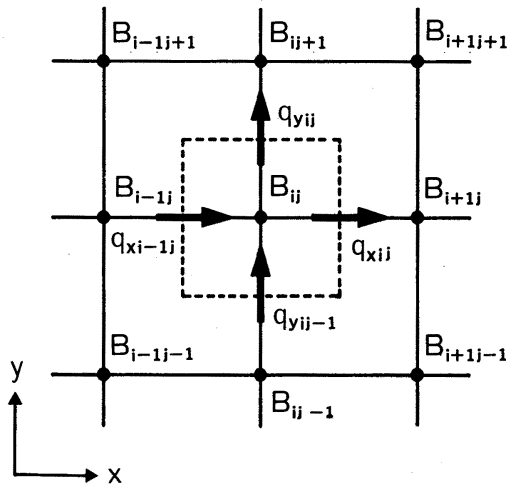

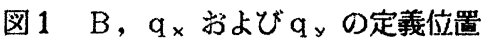

本研究では $\gamma$ の値は0.4 とした。また、砂面を含む流体計算のコントロールボリューム内では、流体の連続 式に対してポーラスボディモデルを用いて、流体の連続性に対する砂面変形の影響を考慮した。なお、砂面 
近傍では液体に対する摩擦抵抗を本来考虑すべきであるが、後述する2次元局所洗掘実験結果との比較で は、フリースリップ条件下で流速分布が良く一致したことから、同条件を採用している。 (d) 流体と砂面形状の計算方法

上記の砂面の変形の計算は、2．1で述べた流体の計算と同時に進めてゅくことが必要である。このこと は、計算の手法上は何ら問題を含まないが、両過程の時間スケールが著しく異なるので多大な計算時間が必 要となり、実用上好ましくない。このため、次のような計算方法をとることとした。(1)STEP-1：ある砂面形 状に対して、流体の数值計算を時間ステップ $\Delta t_{\mathrm{F}}$ で行い、流況がほぼ定常となる $\mathrm{N}_{\mathrm{F}}$ ステップで計算を終 了する。時間 $\Delta t_{F} N_{F}$ における砂面の変形は無視できる程度のものであると見積むられるため、この間は 砂面形状の変形過程の計算は行わない。(2)STEP-2：砂面形状が大きく变化しない範囲では、流況はほほ定常 的であると考えて、STEP-1で得られた一定の流速分布を用いて砂面形状の変形過程の計算のみを行う。この 計算における時間ステップ $\Delta t_{s}$ に関しては、 $\Delta t_{s} \gg \Delta t_{F}$ なる関係が成り立つので、計算時間の大幅な 短縮化が図られる。この計算の $N_{s}$ ステップ後において新たに得られたある点の砂面高さ $B^{N s}$, が、STEP-2 の計算を始める前の砂面高さ $B^{\circ}{ }_{i j}$ および水深 $H^{\circ}{ }_{i j}$ と比較して $\max _{i j}\left\{\left|B^{N s_{i j}}-B^{\circ}{ }_{i j}\right| / H^{\circ}{ }_{i j}\right\} \geqq \varepsilon_{1}$ なる関係が初めて成立した時にSTEP-2の計算が終了する。と，の值は本研究では0.01〜0.02とした。このよ うなSTEP-2の計算が終了した後、再びSTEP-1の計算を行い、流体の移流拡散の過程と砂面形状の変形過程の 計算を進めてゆく。

\section{3. 解析手法の適用性}

3. 12 次元流れ場における局所洗掘現象の数値解析

等温水を用いた2次元喷流による局所洗掘 実験を行い、これに対する数值解析を行なっ た。図 2 に実験水路（長さ $32.5 \mathrm{~m} 、$ 幅 $0.7 \mathrm{~m}$ 、 深さ1.0m）の上流域の鉛直断面を示した。困 中に示されるように、放水口前面から下流 $1340 \mathrm{~mm}$ ま゙は砂面上にコンクリートブロック が敷かれており、この区間では局所洗掘現象 は生じない。これより下流の領域では、砂が $14 \mathrm{~m}$ ほど平滑に敷かれており、砂面形状の変

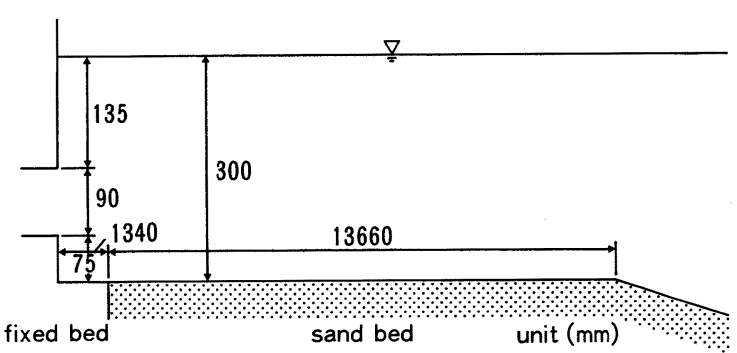

図2 実験水路の上流部分 形が生ずるものとなっている。放水口における平均流速は約 $0.9 \mathrm{~m} / \mathrm{s}$ である。実験では、水路幅中央における 流下方向の 1 次元的な砂面形状を、台車に取り付けた砂面测定機により計测した。

局所洗掘により砂面が最も深く掘れた領域はコンクリートブロックの下流側であり、砂面形状は水路侧壁 面近傍を除いて水路幅方向に大きな変化はなかった。このため、数值解析は水路の上流域のみを対象にし て、鉛直 2 次元平面上で行なった $\left(\Delta x=50 \mathrm{~mm}, \Delta z=15 \mathrm{~mm}, \Delta \mathrm{t}_{\mathrm{F}}=0.015 \mathrm{~s}, \Delta \mathrm{t}_{\mathrm{s}}=6 \mathrm{~s}\right)$ 。図3は、計算によって得られた

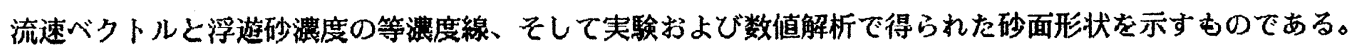
このうち、等濃度線の数值は $\log _{10} \mathrm{C}$ 值に相当する(Cの単位はppm)。図3に示されるように、放水口から 噴出した流れは下方へ向かって進み、固定床に沿う壁面噴流となった後、鉛直方向へ拡散してゅく傾向がみ られる。時間の経過とともに、コンクリートブロックのすぐ後方の砂面上で洗掘が進み、より下流側では洗 掘された砂の一部が堆積し、残りの砂は計算領域外へ運ばれる。実験開始後 4 時間までの各時刻の洗掘形状 は、解析結果とほほ一致しているとみられる。なお、計算領域の下流端では、浮遊砂洒度と掃流砂量の流下 方向の勾配に対して、 $\partial \mathrm{C} / \partial \mathrm{x}=0$ および $\partial^{2} \mathrm{q}_{\mathrm{B}} / \partial \mathrm{x}^{2}=0$ なる条件を用いている。 


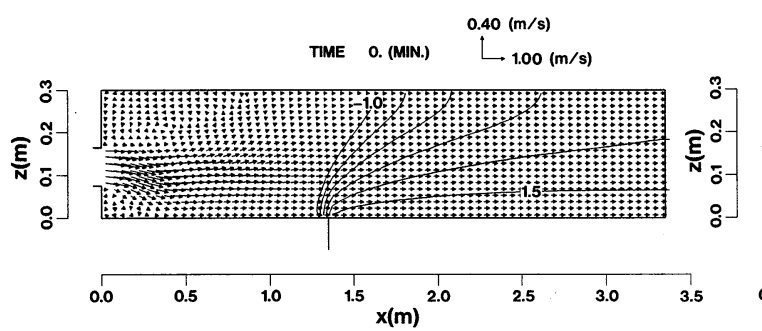

(a)

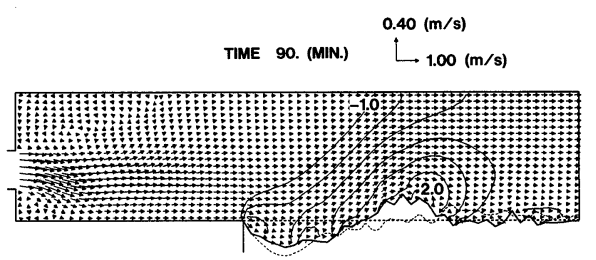

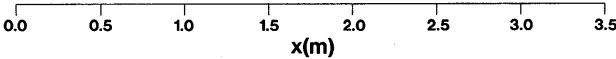

(e)

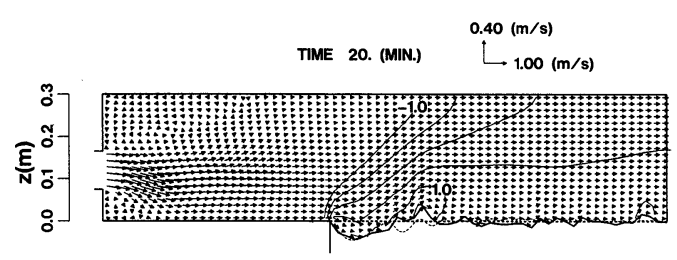

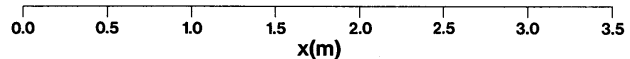

(b)

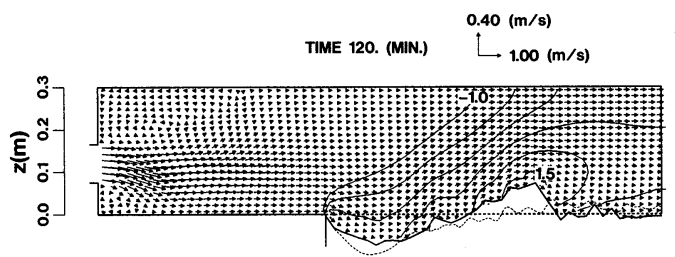

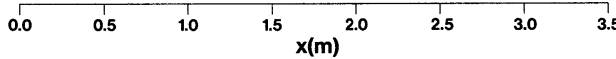

(f)

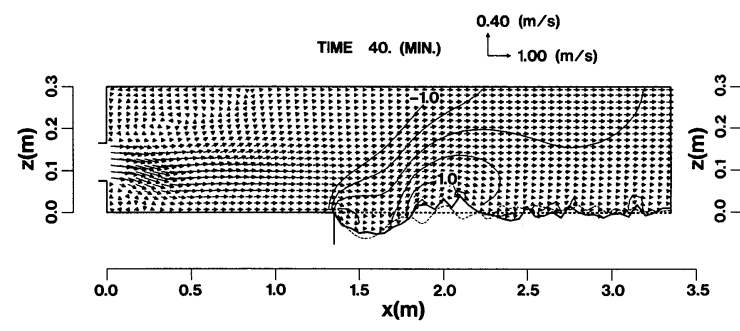

(c)
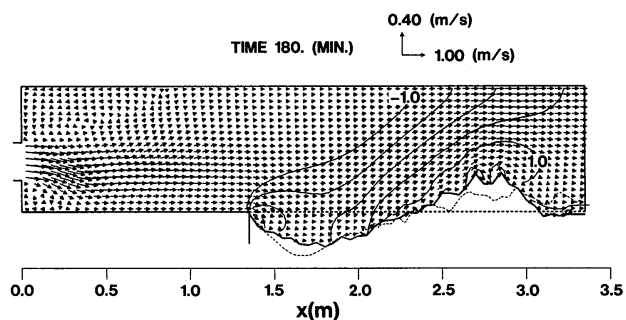

$(g)$

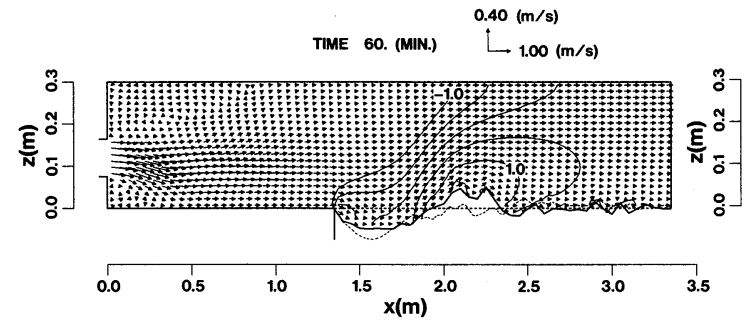

(d)

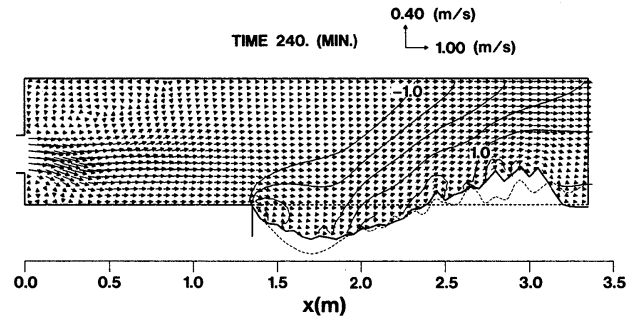

(h)

図3＼cjkstart砂面形状、流速ベクトルおよび等罣度線

（砂面形状のうち、実線：解析結果、細い破線：実験結果、太い破線：初期の砂面形状） 


\section{23 次元流れ場における局所洗掘現象の数値解析}

発電施設から放流される温排水の挙動は、実際には 3次元的なものであるので、洗掘された砂面形状は一 般的には 2 次元的なむのとなる。このような実現象に 近い状熊を再現するために、図4に概略的に示した現 地の約1/20スケールの縮小模型を用いて、局所洗掘実 験を行なった。3個の放水口から流出する等温水の総 流量は、4.66 $\times 10^{-2} \mathrm{~m}^{3} / \mathrm{s}$ である。洗掘された砂面形状 は、測量用の機器により計测された。

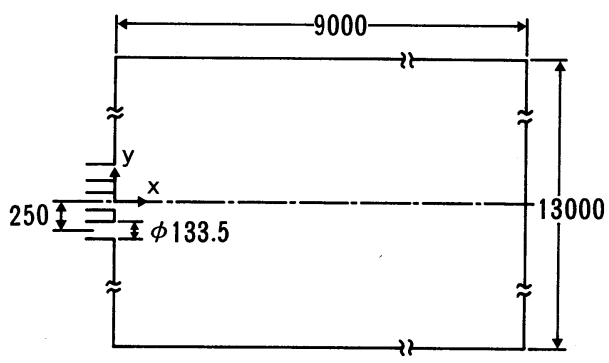

図5は、実験開始から30分後における、実験および 数値解析 $\left(\Delta x=200 \mathrm{~mm}, \Delta y=60 \mathrm{~mm}, \Delta \mathrm{z}=20 \mathrm{~mm}, \Delta \mathrm{t}_{\mathrm{F}}=0.025 \mathrm{~s}\right.$, $\left.\Delta t_{s}=3 s\right)$ で得られた砂面の等高線を示すものである。 これらの結果のうち、実験で得られた等高線の分布は、 砂面形状の概略を示すむので砂面の細かい起伏は描か れていない。実験結果と数値解析結果を比較すると、 最も深く洗掘された点の位置などにやや相違があるが、 おおよその砂面形状はほほ满足に予测されていると思

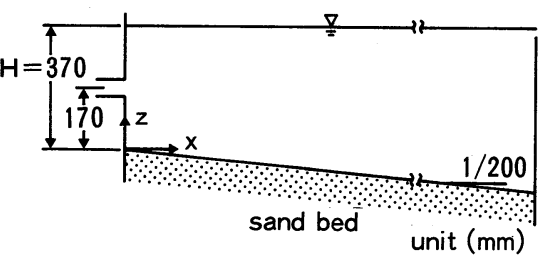

図4実験装置の概略図 われる。次に、放流水の温度が周囲水より $7^{\circ} \mathrm{C}$ 高い条件下での局所洗掘現象の計算を行い、等温条件の結果 と比較した。図6に見られるように、非等温条件下では洗掘の進行がやや遅く、また砂面の起伏が比較的な だらかであるという計算結果が得られた。

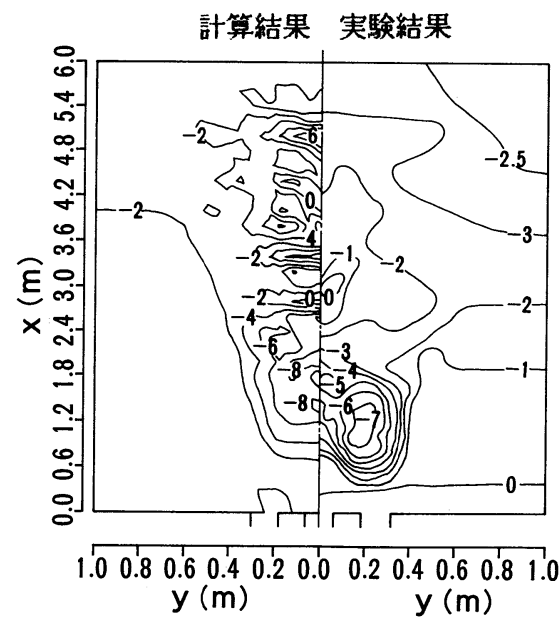

図う実験・解析で得られた砂面の等高線 （放水開始から30分後、図中の数値は、 $\mathrm{z} \mathrm{cm}$ )

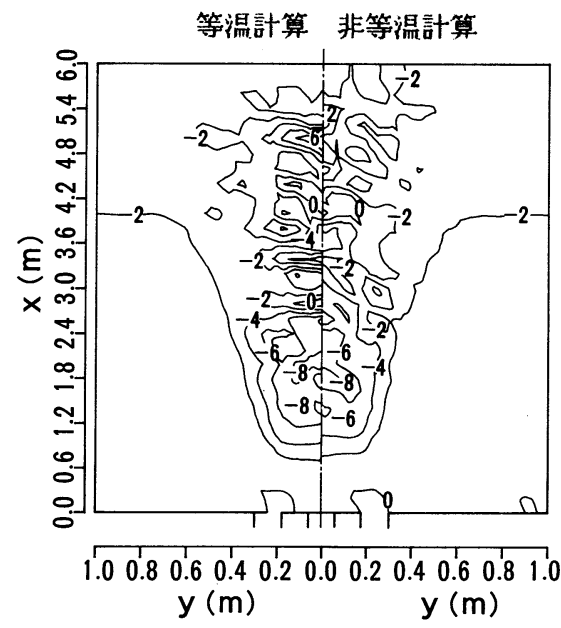

図6 等温・非等温計算で得られた砂面の等高線 （放水開始加ら 30 分後、図中の数値は、 $\mathrm{z} \mathrm{cm}$ ) 


\section{4. おわりに}

本研究では、温排水の水中放流により生ずる海底の砂面の局所洗掘現象を予測する数値解析手法の検討を 行った。水理実験結果との比較から、数値解析手法の適用性は概ね良好であると考えられる。なお、今後の 課題として、砂面近傍の境界条件等の改良や波浪の影響を考虑することなどが考えられる。また、現地の実 测データが入手できればそれとの此較検討も行いたい。

\section{《参考文献》}

1)Rouse,H., Proc. Hydraul. Conf. Univ. of lowa, Bull.20, 1940.

2)Dodd iah,D., Proc. Minesota Int.Hydraul. Conf., IAHR, 1953.

3)岩垣・土屋・今村, 京大防災年報第8号, 昭40.

4)Tsuchiya,Y. \& Iwagaki,Y., Proc. 12th Cong. IAHR, 1967.

5)斎藤, 土木学会論文集第282号, 1979.

6)Chatter jee,S. S. \& Ghosh,S.N., J. Hydraul. Div., Proc.ASCE, Vol.106, No.HY11, 1980.

7)Hassan, N.M.K.N. \& Narayanan, R., J. Hydraul. Eng., ASCE, Vol.111, No.11, 1985.

8)Shimizu,Y. \& I takura,T., J. Hydraul. Eng., Vol.115, No.3, 1989.

9)芦田・江頭・劉, 水工学論文集, 1991 .

10)Akiyama,J., Hong,L.D., and Ura.M,水工学論文集, 1991.

11)和田・片野・荒木, 電中研研究報告, 1982 .

12)和田・荒木, 電中研研究報告, 1986 .

13)松井・岩佐・細田, 土木学会年講, 1984.

14)室田・中辻, 水講論文集, 1986 .

15)松梨・岡田・黒林, 水講論文集, 1987.

16)Ushijima,S. \& Moriya,S, Proc. 3rd Int. Symp. on RFMTM, 1988.

17)Launder,B.E., J. Fluid Mech., Vol.67, 1975.

18)芦田・高橋・水山, 新砂防, 107, 1978.

19)岩佐, 水理学, 朝倉書店, 昭55.

20)Lane,E.W. \& Kalinske,A.A., Trans. AGU, Vol.22, 1941. 